\title{
Role of beneficial microorganisms in Sustainable Agriculture
}

J Selva Andina Biosph. 2020;8(2):67-68.

Currently, there is a worldwide trend to develop "sustainable agriculture" in order to reduce the use of chemical pesticides that pollute the environment (air, soil and water) and promote the use of beneficial microorganisms in the different production systems, but that have not been considered within the crop agronomic management plans or as a component of the crop integrated management ${ }^{1}$. Sustainable agriculture aims to produce a sufficient amount of food to meet current and future demand through the efficient use of natural resources, in order to generate income for the farmer, produce clean products with less impact on the environment.

The world's small farmers, especially those in developing countries, face problems related to agricultural activity, such as the low price they obtain for the products harvested, the increase in production costs, the lack of qualified labor in the countryside and the degradation of natural resources, due to the excessive use of soil and chemicals, and even the effects caused by climate change. However, these types of farmers can provide the key to a better future, with the generation of agricultural products based on clean agriculture that allows taking care of their health and that of consumers, as well as the environment in which they carry out their productive activity. The use of beneficial microorganisms (MB) such as fungi, bacteria or viruses, constitutes a basic tool, and very useful for the development of a clean and friendly agriculture with the productive environment. Many scientific studies have been carried out to demonstrate the benefits of MB in different food security crops such as potatoes, rice, corn, among others, and perennial crops, such as fruit trees that have nutraceutical traits for which they are highly appreciated.

Among the main microorganisms used in agriculture, there are fungi of the genera Trichoderma and Beauveria, and different species of mycorrhizae, as well as bacteria of the genus Bacillus. These biological agents have proven their efficiency in pest control through different mechanisms of action such as antibiosis, mycoparasitism or competition. In addition, they have confirmed their effect as plant growth promoter organisms, especially at the level of root biomass and their incidence in improving the nutrient absorption such as $\mathrm{N}$ and $\mathrm{Ca}$, elements that are related to cell division, structure of cell walls, and plant growth. They have even had an impact on crop yields, increasing production by up to $20 \%$.

However, the success of the use of MB is based on its effectiveness and efficiency, which must be demonstrated to farmers through demonstrative experimental plots in order to produce a real impact on its adoption in agriculture. 
The successful adoption of MB in the production systems of small farmers has confirmed the benefit of a participatory approach to agricultural systems to lead towards the economic development of this sector and constitute an alternative that allows access to local and international markets in order to find niches that pay a better price for this type of product and make sustainable agriculture profitable.

The use of formulations (soluble powders, emulsifiable concentrate, covered and dispersible granules) provides alternatives that allow improving the quality of a bio-input, guaranteeing its efficiency, as well as its storage and shelf life. This type of technology has been developed in industrialized countries and is being applied in agricultural systems both for local production and for export products with high quality standards.

It is required that State policies are adopted that promote the use of biocontrollers with the support of extension agents and scientists that will allow the development of new technologies and methods of application of this type of microorganism.

Processes must be integrated throughout the entire agricultural production chain, and critical evaluation and emphasis on quality control must be maintained at every step of the bio-input production process. These actions will allow a country to achieve the Sustainability Goals of the United Nations Organization for the benefit of the agricultural sector.

\section{Cited Literature}

1. Viera W, Jackson T. Ecuador demonstrates a sustainable way forward for small farmer producers. Chron Horticult 2020;60(3):19-21.

Viera-Arroyo William Fernando National Institute of Agricultural Research. (INIAP)

Av. Eloy Alfaro N30-350 y Amazonas

Quito. Ecuador

Tel: +59322567645

Email: william.viera@iniap.gob.ec 